\author{
Departamento de Apoio \\ à Gestão Participativa, \\ Secretaria de Gestão \\ Estratégica e Participativa, \\ Ministério da Saúde
}

\author{
Correspondência | Correspondence: \\ Esplanada dos Ministérios Bloco G \\ Ministério da Saúde, edifício sede \\ Secretaria de Gestão Estratégica e Partici- \\ pativa Sala 419 \\ 70058-900 Brasília, DF, Brasil
}

Texto de difusão técnico-científica do Ministério de Saúde.

\section{Saúde da população de gays, lésbicas, bissexuais, travestis e \\ transexuais}

\author{
Health of gay, lesbian, bisexual, \\ transgender and transsexual \\ population
}

O direito à saúde no Brasil está garantido na Constituição e é fruto da grande mobilização política da sociedade, que envolveu e comprometeu as instituições públicas e o conjunto da Assembléia Nacional Constituinte. Essa luta ganhou o nome de "Movimento pela Reforma Sanitária" brasileira. A partir da Constituição de 1988, a saúde passou a ser integrante do Sistema de Seguridade Social em decorrência do conceito de saúde adotado, ou seja o de que a saúde é o resultado do acesso das pessoas e coletividades às políticas, aos bens e serviços sociais que promovem a qualidade de vida.

Isso quer dizer que, para ter saúde, é necessário satisfazer, dentre outras, as necessidades de educação, moradia, emprego, alimentação, lazer e transporte. Esse é o chamado conceito ampliado de saúde, no qual saúde não é somente a ausência de doença. Para que uma população tenha saúde, é necessário que todos os setores das políticas sociais se articulem, gerando, de fato, uma interferência eficaz sobre os determinantes sociais da saúde. Dessa forma obtêm-se mudanças efetivas na qualidade de vida e no nível de saúde da população.

Enfrentar a complexidade dos determinantes sociais da vida e da saúde das pessoas e coletividades requer intervir sobre exclusão social, desemprego, bem como acesso digno a moradia e alimentação. Requer também o reconhecimento dos fatores que se entrecruzam, maximizando a vulnerabilidade e o sofrimento de grupos específicos. Nesse contexto, todas as formas de discriminação, como no caso da homofobia, devem ser consideradas como situações produtoras de doença e sofrimento. É preciso compreender, por outro lado, que a homofobia não ocorre de maneira isolada de outras formas de discriminação social. Ela caminha ao lado e se reforça pelo machismo, o racismo, a misoginia e todas as formas correlatas de discriminação.

A visão ampliada e integral da saúde tal como inscrita na nossa Constituição, é uma conquista da sociedade brasileira, mas o País ainda está muito distante de ver tais princípios consolidados no cotidiano das pessoas. Para que isso aconteça é necessário que toda a população e todos os movimentos sociais se apropriem de capacidade crítica e política para exigir as melhorias necessárias à qualidade de vida. No entanto, é importante lembrar que, independentemente das melhorias das condições de vida e de níveis de saúde, as situações de desequilíbrio, vulnerabilidades e riscos sempre irão demandar por serviços de atenção e cuidado à saúde. Portanto, fez-se necessária a criação de um sistema de serviços para ofertar à população brasileira todas as ações assistenciais de que ela necessita - o Sistema Único de Saúde (SUS).

O SUS, que também foi criado pela Constituição, está baseado em um conjunto de princípios e o primeiro deles é a universalidade. Isso significa que todos têm direito ao acesso gratuito aos seus serviços de saúde. O SUS deve ser integral, ou seja, deve oferecer todas as modalidades de atendimento que as pessoas e as comunidades necessitam: desde iniciativas e ações de promoção e prevenção até as mais especializadas. $\mathrm{O}$ SUS deve ter a participação da comunidade, pelo entendimento de que esta é a forma pela qual os usuários e usuárias vocalizam suas necessidades e demandas. Para dar concretude à participação popular, foram criados os conselhos e as conferências de saúde para o exercício do controle social, voltado à analise e aprovação das diretrizes, planos e programas de saúde e monitoramento, avaliação e fiscalização da gestão e execução de planos e programas.

Entender as intenções e os sentidos que fundamentam o movimento da reforma sanitária e o SUS como conquista é muito importante, pois significa também ampliar a consciência sobre o direito à saúde. Foi por esta via que o povo brasileiro conseguiu definir a responsabilidade do Estado pela saúde, contrariando aqueles que querem fazer da saúde mercadoria e fonte de lucro. É necessário ter sempre presente que o SUS é uma política contra-hegemônica e que, por isso, permanentemente 
sofre ataques que visam a reduzir as conquistas sociais no campo da saúde. O SUS sobrevive às freqüentes ofensivas do segmento privado da saúde e de uma parcela dos políticos, gestores e órgãos da mídia, porque dispõe de uma forte mobilização popular na sua base de sustentação. Contudo, essa mobilização precisa crescer e se diversificar, pressionando cada secretaria estadual e municipal de saúde e seus componentes para que o Brasil possa finalmente consolidar o SUS como um sistema justo, equânime e de qualidade para todos.

O Ministério da Saúde acumula duas décadas de atenção à população de gays, lésbicas, bissexuais, travestis e transexuais (GLBT), que partiram do enfrentamento da epidemia da Aids. Nesse sentido, o Ministério da Saúde tem apoiado projetos nas áreas da prevenção das infecções sexualmente transmissíveis (IST), disponibilizado assessoria jurídica e fortalecimento de redes, desenvolvido campanhas de comunicação e ações para visibilidade da população GLBT como estratégia de promoção da saúde e promovido a participação do movimento GLBT em instâncias consultivas.

No âmbito institucional desde 2007, o Ministério da Saúde tem trabalhado na construção do Plano Integrado de Enfrentamento da Feminização da Epidemia de Aids e outras IST, com ações para mulheres lésbicas, bissexuais e transexuais; e do Plano Nacional de Enfrentamento da Epidemia de Aids e das IST entre gays, homens que fazem sexo com homens (HSH) e travestis.

Com o atual alargamento da perspectiva da integralidade da atenção à saúde desses segmentos populacionais brasileiros, reconhece-se que a orientação sexual e a identidade de gênero constituem situações muito mais complexas e são fatores de vulnerabilidade para a saúde. Tal reconhecimento deve-se não apenas por implicarem práticas sexuais e sociais específicas, mas também por exporem a população GLBT a agravos decorrentes do estigma, dos processos discriminatórios e de exclusão social, que violam seus direitos humanos, entre os quais, o direito à saúde, à dignidade, à não-discriminação, à autonomia e ao livre desenvolvimento.

O Programa Brasil sem Homofobia, lançado pelo governo federal em 2004, foi criado para a formulação de políticas e programas específicos na intenção da melhoria da situação de vida dos grupos GLBT. Como resposta, foi criado Comitê Técnico de Saúde da População GLBT (Portaria No 2.227, do Gabinete do Ministro, de 14 de outubro de 2004) no Ministério da Saúde. Coordenado pela Secretaria de Gestão Estratégica e Participativa (SGEP), esse Comitê se constitui em espaço de articulação, debate e ausculta de demandas de representações do movimento social, envolvendo todas as áreas atinentes do Ministério da Saúde, no sentido de promover a inserção das especificidades de saúde desse contingente populacional nas políticas e ações do SUS.
O comitê integra um conjunto de estratégias de área de "Promoção de Equidade" da SGEP, por meio do Departamento de Apoio à Gestão Participativa (DAGEP), onde também se inserem os comitês específicos voltados às populações: negra, quilombolas, ciganos, pessoas em situação de rua e populações do campo e da floresta. Esta estratégia de comitês tem como característica comum a articulação de ações voltadas para promoção de ações diferenciadas de saúde, com o objetivo de reduzir desigualdades de grupos em condições de exclusão social e iniqüidade em saúde. Muitos avanços podem ser contabilizados em decorrência dessas estratégias de trabalho.

Um desses avanços foi a realização do Seminário Nacional de Saúde da População GLBT na Construção do SUS, em agosto de 2007, no qual governo e movimentos sociais avaliaram as iniciativas que vem sendo adotadas. Entres estas citam-se a inclusão de demandas das lésbicas nas políticas de saúde da mulher e o processo transexualizador, em avançada fase de inclusão entre os procedimentos rotineiros do SUS, mantendo-se a visão crítica sobre a medicalização das transexualidades. Da mesma forma, deve-se destacar a inclusão da identidade de gênero na carta dos Direitos dos Usuários do SUS, que completa a histórica reivindicação do movimento, com o direito ao uso do nome social nos cadastros do SUS. Outra importante conquista política das populações GLBT é a sua atual representação no Conselho Nacional de Saúde.

A $13^{\text {a }}$ Conferência Nacional de Saúde, cuja etapa nacional ocorreu em novembro de 2007, trouxe a evidência da maturidade deste debate, expressa no conjunto de demandas e propostas ali discutidas. Entre elas citamse: inclusão e articulação das especificidades de orientação sexual e identidade de gênero em uma política nacional voltada para as populações GLBT; necessidade de implementação de práticas de educação permanente para os profissionais de saúde incluindo a temática GLBT; definição de normas não-discriminatórias sobre a doação de sangue, preservando-se o controle de risco; realização de pesquisas científicas, inovações tecnológicas e compartilhamento dos avanços terapêuticos relativos ao tema; respeito ao direito à intimidade e à individualidade dos grupos e indivíduos pertencentes às populações GLBT; necessidade de adotar o protocolo de atenção às pessoas em situação de violência; garantia dos direitos sexuais e reprodutivos extensiva a esses segmentos; implementação de campanhas e revisão dos currículos escolares; e mudanças nos formulários, prontuários e sistemas de informação do SUS.

De fato, as deliberações da $13^{\mathrm{a}} \mathrm{CNS}$ refletiram o próprio debate do Seminário, reforçando as diversas demandas ao Ministério da Saúde e ao SUS. No momento, é necessário que as deliberações desta Conferência Nacional GLBT aprofundem e ratifiquem o conjunto dessas demandas. Mais importante ainda é a ampliação 
da consciência de que essas demandas devem repercutir não apenas no âmbito do Ministério da Saúde, mas sobre os conselhos de saúde e as respectivas secretarias estaduais e municipais de saúde, reais instâncias executoras dos serviços do SUS.

O desafio da promoção da eqüidade para a população GLBT deve ser compreendido a partir da perspectiva das suas vulnerabilidades específicas, demandando iniciativas políticas e operacionais que visem à proteção dos direitos humanos e sociais dessas populações. Há um consenso sobre a necessidade do combate à homofobia no SUS, tendo como base o conceito de saúde da Organização Mundial da Saúde (OMS), que entende que a proteção do direito à livre orientação sexual e identidade de gênero não é apenas uma questão de segurança pública, mas envolve também, de maneira significativa, questões pertinentes à saúde mental e a atenção a outras vulnerabilidades atinentes a esses segmentos. $\mathrm{O}$ combate à homofobia é uma estratégia fundamental e estruturante para a garantia do acesso aos serviços e da qualidade da atenção.

Por outro lado, uma política de enfrentamento das iniqüidades da população GLBT requer iniciativas estratégicas vigorosas, entre as quais a capacitação dos profissionais de saúde sobre as práticas sexuais e sociais de GLBT. Esta é questão fundamental para que o cuidado seja condizente com suas reais necessidades em saúde, superando a estrita associação da saúde dessas populações à epidemia de HIV/Aids.

O Ministério da Saúde está fazendo a sua parte, envolvendo-se séria e definitivamente na promoção de maior eqüidade em saúde de todos os grupos populacionais vulneráveis do país. Entretanto as políticas formuladas pelo Ministério da Saúde são para a execução do sistema, ou seja, de toda a rede de serviços municipais e estaduais. A expectativa é que as deliberações desta Conferência Nacional de Gays, Lésbicas, Bissexuais, Travestis e Transexuais deverão ter em conta que a efetividade do acolhimento das necessidades de saúde desta população depende, em contrapartida, da inserção vigorosa dos movimentos sociais GLBT na defesa do SUS. Assim, é indispensável a ampliação da participação desse contingente da sociedade nos espaços participativos formais e alternativos já existentes e naqueles que, a partir de agora, poderão e deverão ser criados.

\section{Estratégias de Gestão e de Ação}

As ações que vem sendo desenvolvidas à população GLBT são:

- Sensibilizar gestores e gerentes públicos da saúde sobre os efeitos da homofobia, lesbofobia e transfobia como elemento da vulnerabilidade, que gera obstáculos ao acesso e à promoção da equidade da população GLBT.
- Implantar e implementar instâncias de Promoção da Eqüidade na Saúde da População GLBT no âmbito das gestões estaduais e municipais.

- Garantir a participação dos segmentos GLBT nas instâncias dos conselhos e conferencias de saúde, para interferir na formulação de políticas públicas e atuar no controle social do SUS.

- Incluir os conteúdos relacionados à população GLBT na formação dos profissionais da saúde de nível técnico e da graduação, bem como garantir o tema nos processos de Educação Permanente em serviço dos profissionais do SUS.

- Incluir os quesitos étnico-racial, orientação sexual e identidade de gênero nos formulários e sistemas de informação do SUS.

- Garantir apoio técnico e institucional aos movimentos sociais GLBT para fortalecimento da consciência do direito à saúde e em defesa do SUS.

- Organizar redes integradas de atenção à população GLBT em situação de violência doméstica, sexual e social, em parceria com os Centros de Referência GLBT/Secretaria Especial dos Direitos Humanos.

- Implantar a Carta dos Direitos dos Usuários da Saúde como rotina dos serviços, garantindo a inclusão do nome social nos prontuários de atendimento, no cartão SUS e ficha de Equipe de Saúde da Família dos serviços de saúde.

- Combater a homofobia institucional com ampliação do atendimento humanizado no SUS.

- Fomentar realização de pesquisas e produção de conhecimento em saúde da população GLBT.

- Fortalecer a atenção básica ampliando e garantindo o acesso à população GLBT, promovendo a integralidade e a equidade da atenção integral à saúde.

- Reconhecer e incluir nos sistemas de informação do SUS, todas as configurações familiares, para além da heteronormatividade.

- Qualificar a atenção básica no cuidado aos idosos GLBT, dando continuidade ao processo de implantação e implementação da Caderneta de Saúde da Pessoa Idosa e a atenção domiciliar humanizada ao idoso GLBT.

- Garantir atenção à saúde integral e os direitos sexuais e reprodutivos em todas as fases de vida, para as mulheres lésbicas, bissexuais e transexuais, nos âmbito do SUS.

- Implementar e aperfeiçoar as ações de enfrentamento da epidemia de AIDS e outras IST junto à população GLBT. 
- Implantar e implementar a assistência em urologia e proctologia para homens gays, bissexuais e travestis nos estados e municípios, dentro da perspectiva da Política de Saúde Integral do Homem.

- Implantar os Centros de Referência com Assistência Interdisciplinar a Transexuais garantindo a assistência endocrinológica integral para travestis e transexuais.

- Elaborar e regulamentar os Protocolos do Processo Transexualizador no SUS.

- Fomentar a realização de pesquisas e estudos para produção de protocolos e diretrizes a respeito da hormonioterapia, implante de próteses de silicone e retirada de silicone industrial para travestis e transexuais.

- Qualificar a atenção à saúde mental em todas as fases de vida da população GLBT prevenindo os agravos decorrentes dos efeitos da discriminação, do uso de álcool e outras drogas e da exclusão social.

- Promover a humanização da atenção à saúde da população GLBT em situação carcerária.

- Desenvolver ações e práticas de educação em saúde nos serviços do SUS com ênfase na orientação sexual e identidade de gênero.

- Garantir a extensão do direito à saúde suplementar ao cônjuge dependente entre os casais GLBT.

- Garantir o acesso universal e integral de reprodução humana assistida às mulheres lésbicas e bissexuais em idade reprodutiva.

- Implementar ações de vigilância, prevenção e atenção a violência contra homossexuais. 